\title{
Probing the Sinorhizobium meliloti-Alfalfa Symbiosis Using Temperature-Sensitive and Impaired-Function Citrate Synthase Mutants
}

\author{
Wojciech Grzemski, James P. Akowski, and Michael L. Kahn \\ Institute of Biological Chemistry, Washington State University, Pullman 99164-6340, U.S.A.
}

Submitted 16 June 2004. Accepted 10 September 2004.

\begin{abstract}
To study the role of the decarboxylating leg of the bacterial TCA cycle in symbiotic nitrogen fixation, we used DNA shuffling and localized random polymerase chain reaction mutagenesis to construct a series of temperature-sensitive and impaired-function mutants in the Sinorhizobium meliloti Rm104A14 citrate synthase ( gltA) gene. Reducing citrate synthase (CS) activity by mutation led to a corresponding decrease in the free-living growth rate; however, alfalfa plants formed fully effective nodules when infected with mutants having CS activities as low as $7 \%$ of the wild-type strain. Mutants with approximately $3 \%$ of normal CS activity formed nodules with lower nitrogenase activity and a mutant with less than $0.5 \%$ of normal CS activity formed Fix $^{-}$nodules. Two temperature-sensitive ( $\left.t s\right)$ mutants grew at a permissive temperature $\left(25^{\circ} \mathrm{C}\right)$ with $3 \%$ of wild-type $\mathrm{CS}$ activities but were unable to grow on minimal medium at $30^{\circ} \mathrm{C}$. Alfalfa plants that were inoculated with the $t s \mathrm{mu}-$ tants and grown with a root temperature of $20^{\circ} \mathrm{C}$ formed functional nodules with nitrogenase activities approximately $20 \%$ of the wild type. When the roots of plants infected with the $t s$ mutants were transferred to $30^{\circ} \mathrm{C}$, the nodules lost the ability to fix nitrogen over several days. Microscopic examination of these nodules revealed the loss of bacteroids and senescence, indicating that CS activity was essential for nodule maintenance.
\end{abstract}

Additional keyword: Rhizobium.

Rhizobia are bacteria that can form nitrogen-fixing symbiotic associations, usually with a legume host. Bacterial infection of the plant root leads to development of a new organ, the root nodule, in which nitrogen fixation can take place. Nodule formation, a complex process that involves altered expression of specific host and rhizobial genes, is guided by the exchange of signals and metabolites between the plant and bacteria (Broughton et al. 2000; Kistner and Parniske 2002; Long 2001; Patriarca et al. 2002; Spaink et al. 1998; Stougaard 2000). During infection, the bacteria enter the plant cells and differentiate into nitrogen-fixing bacteroids. The host plant supplies bacteroids with carbon compounds, including dicarboxylic and amino acids (Kahn et al. 1998; Lodwig et al. 2003). These are used by the bacteroids to support the reduction of dinitrogen to ammonia in amounts sufficient for plant growth (Parsons and Sunley 2001; Udvardi and Day 1997).

Corresponding author: M. L. Kahn; Telephone: 509-335-8327; Fax: 509335-7643; E-mail: kahn@wsu.edu
The pathways used by bacteroids for dicarboxylate catabolism are still unclear. Null mutants in several TCA cycle genes block nitrogen fixation (Dunn 1998; Kahn et al. 1998), but in situations where bypass reactions exist or several genes contribute to an enzyme's activity, fixation can be normal or only slightly impaired (Green et al. 2000; Hernandez-Lucas et al. 1995; Thony-Meyer and Kunzler 1996). In Sinorhizobium meliloti, mutants in two TCA cycle genes, isocitrate dehydrogenase $(i c d)$ and citrate synthase $(g l t A)$, differ in their nodulation phenotypes (McDermott and Kahn 1992; Mortimer et al. 1999). The icd mutants form ineffective but normal-looking nodules that have abundant bacteroids within the infected cells, whereas gltA mutants form empty nodules, completely lacking intracellular bacteria. S. fredii gltA mutants have a similar ineffective phenotype, although some bacteroids are present (Krishnan et al. 2003). The difference in phenotype for the $S$. meliloti mutants was surprising because both mutants are affected in the decarboxylating leg of the TCA cycle and have similar nutritional phenotypes, such as a requirement for glutamate. The gltA mutants clearly are unsuitable for experiments to determine whether citrate synthase (CS) is essential during nitrogen fixation in a mature nodule because they have an obvious defect in development that prevents them from forming normal bacteroids. Nodules formed by the icd mutants appear more normal; therefore, it is tempting to think that their defect is due more to metabolic dysfunction than to a failure to differentiate properly. Obviously, at late stages of nodule development, these two types of explanation for an ineffective phenotype are very difficult to separate experimentally.

One difference between the two mutants is in their exopolysaccharides; gltA mutants make an exopolysaccharide I (EPSI) succinoglycan lacking the normal level of succinate modification. exoH mutants, which are unable to succinylate EPSI, also form empty nodules but have been shown to form normal nodules if a low molecular weight fraction of EPSI is added during infection (Battisti et al. 1992; Leigh and Walker 1994; Urzainqui and Walker 1992). We speculated that, if the gltA mutants had a similar EPSI problem but we could get nodules to start developing, then subsequent maturation would continue normally. Although we might have tried complementing the gltA mutants with EPSI, a later defect in development also might interfere with development, but in a more cryptic way. Therefore, we decided to try a new approach to investigating metabolic interactions in this system by isolating temperaturesensitive $(t s)$ gltA mutants. These would be able to form nitrogen-fixing nodules at the permissive temperature but, after nodule development was complete, we should be able to raise the root temperature and remove CS. If CS was essential only in the early stages of infection because it was used to make 
EPSI, the nodules should continue fixing nitrogen after the temperature shift. This is not what we report-at the higher temperature, bacteroids of the gltA $t s$ strain were rapidly degraded. We conclude that, although CS may be needed during nodule formation, it also is required to maintain bacterial integrity within the nodules.

Using $t s$ mutants to study bacterial metabolism and as probes of developmental processes is not a new concept. These $t s$ mutants often are selected to have insufficient enzyme activity at very low or very high temperatures, conditions that may be at the limit of the normal physiological range (Hooke 1994; Sakano et al. 1974). In this case, we had to find $t s$ mutants that were affected within a relatively normal temperature range for alfalfa nitrogen fixation, which has a broad temperature optimum, with values at 18 and $28^{\circ} \mathrm{C}$ that are approximately $80 \%$ of the maximum (Rice and Olsen 1988). For S. meliloti Rm104A14, a major challenge was to construct a mutant that had insufficient $\mathrm{CS}$ activity at $30^{\circ} \mathrm{C}$, an optimal temperature for $S$. meliloti growth. While searching for gltA ts mutants, we isolated several mutants with lower than normal CS activities that still were able to grow in the absence of a glutamate or arabinose supplement. These partial-function mutants allowed us to show that a surprisingly low level of CS can support normal nitrogen fixation, and their behavior provides a context for interpreting the behavior of the $t s$ mutants.

\section{RESULTS AND DISCUSSION}

Isolation of partial-function gltA mutants.

The CS gene from $S$. meliloti Rm104A14 originally was isolated in a 9.0-kb DNA fragment (Mortimer et al. 1999). We subcloned a 5.6-kb PstI-SacI fragment that contains the CS gene into the suicide vector pJPA22 to give plasmid pMK500. pMK500 was electroporated into Escherichia coli S17-1 and transferred by conjugation into the CS deletion mutant $S$. meliloti $\Delta 1 \mathrm{~A}$, selecting for resistance to tetracycline at 1 $\mu \mathrm{g} / \mathrm{ml}$. The CS activity of the resulting $S$. meliloti strain MK500 was $197.1 \pm 0.6 \mathrm{nmole} / \mathrm{min} / \mathrm{mg}$ of protein, approximately $60 \%$ of wild-type Rm104A14 (Table 1). A lower CS activity $(137.2 \pm 3.1 \mathrm{nmole} / \mathrm{min} / \mathrm{mg}$ of protein) was obtained when pMK501, a plasmid carrying the $1.8-\mathrm{kb}$ CS fragment generated by polymerase chain reaction (PCR) with CS1 and CS2 primers (Fig. 1), was integrated into the $S$. meliloti $\Delta 1 \mathrm{~A}$ chromosome to give strain MK501. After this single recombination, the functional copy of gltA was in a normal context; however, there was a second copy of sequences derived from flanking regions of citrate synthase located either upstream or downstream. These or other plasmid sequences remaining on the chromosome may have interfered with expression of CS, resulting in reduced activity.

Mutant plasmids pMK502-pMK507 were constructed by localized random PCR mutagenesis. After PCR using primers CS1 and CS2 with pMK501, the PCR product was cloned into
pJPA22 using SacI and PstI and electroporated into E. coli MOB154, a glutamate auxotroph (Mortimer et al. 1999). In all, 18 mutants with a reduced growth rate were selected as small, tetracycline-resistant colonies on M9-glucose agar. Plasmid DNA isolated from these mutants was electroporated into $E$. coli $\mathrm{S} 17-1$ and integrated into the $S$. meliloti $\Delta 1 \mathrm{~A}$ chromosome by biparental mating, selecting for tetracycline resistant recombinants able to grow on minimal mannitol ammonia $\left(\mathrm{MMNH}_{4}\right)$ media lacking arabinose, which serves as a source of 2-oxoglutarate. CS activity was measured and six strains with reduced $\mathrm{CS}$ activity were selected. Because the $s a c B$ gene product, levansucrase, might interfere with effective nodulation (McDermott and Kahn 1992), the $s a c B$ gene carried by pJPA22 was eliminated from the mutagenized recombinants by growing them on minimal media supplemented with $5 \%$ sucrose. We confirmed that plasmid DNA integrated into the $S$. meliloti $\triangle 1 \mathrm{~A}$ chromosome by PCR with CS1 and CS2 primers. All mutants contained a $0.6-\mathrm{kb}$ fragment, corresponding to the sequences flanking the gltA open reading frame (ORF), and a 1.8-kb fragment, corresponding to the integrated mutant CS. These two PCR fragments were expected after a single recombination. However, further PCR analysis with the CS1, CS2, $\alpha-\mathrm{V}$, and $\beta-\mathrm{D}$ primers revealed that, contrary to the expectation that a second homologous recombination would delete pJPA22 and the deletion allele of gltA, some pJPA22 plasmid DNA still remained in the mutagenized derivatives after the selection for sucrose resistance. The length of this DNA varied from 2 to 7 $\mathrm{kb}$, depending on the strain.

CS activity was measured in these strains and is reported in Table 1. The growth rate of the partial-function mutants in $\mathrm{MMNH}_{4}$ medium was correlated with the CS activity (Fig. 2). We have not determined the degree of EPSI succinylation by chemical methods; however, all mutants except MK507 had a normal appearance when grown on Calcofluor agar, indicating that they were able to synthesize succinylated EPSI (Mortimer et al. 1999) and suggesting that the defect in CS must be almost complete to give a Calcofluor-minus phenotype.

Table 1. Citrate synthase activities of gltA mutant strains

\begin{tabular}{lc}
\hline Sinorhizobium meliloti strain & $\begin{array}{c}\text { Citrate synthase activity } \\
\text { (nmole/min/mg of protein) }\end{array}$ \\
\hline$\Delta 1 \mathrm{~A}$ & $0.0 \pm 0.0$ \\
Rm104A14 & $336.9 \pm 6.1$ \\
MK500 & $197.1 \pm 0.6$ \\
MK501 & $137.2 \pm 3.1$ \\
MK502 & $92.6 \pm 0.2$ \\
MK503 & $80.6 \pm 0.4$ \\
MK504 & $44.9 \pm 0.3$ \\
MK505 & $27.9 \pm 0.3$ \\
MK506 & $12.9 \pm 0.1$ \\
$\Delta 1 \mathrm{~A}(\mathrm{pMK511)}$ & $9.7 \pm 0.1$ \\
$\Delta 1 \mathrm{~A}(\mathrm{pMK512)}$ & $9.2 \pm 0.2$ \\
MK507 & $1.2 \pm 0.2$ \\
\hline
\end{tabular}

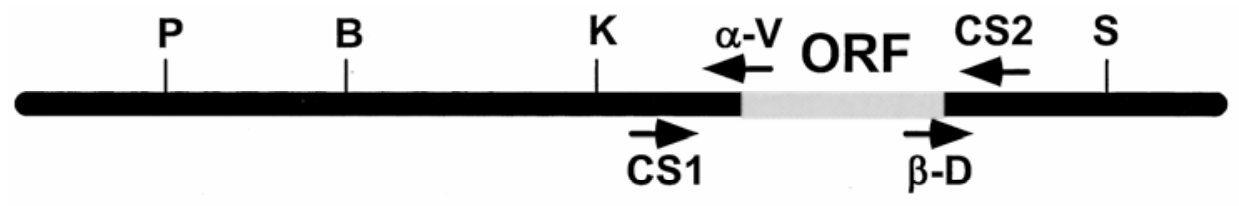

\section{$5.6 \mathrm{~kb}$}

\section{$1.8 \mathrm{~kb}$}

Fig. 1. Polymerase chain reaction (PCR) primers used in plasmid constructions. The Sinorhizobium meliloti Rm104A14 citrate synthase open reading frame $(\mathrm{ORF})$ is indicated. The orientation and approximate position of the PCR primers are shown with arrows. $\mathrm{P}=$ Pst $\mathrm{I} ; \mathrm{B}=$ BglII; K $=$ KpnI; $\mathrm{S}=$ Sac I. 
Temperature-sensitive mutants.

The $t s$ mutants were constructed by DNA shuffling of the 1.8-kb gltA fragment (Fig. 1). The mutagenized CS DNA was subcloned into pCPP30 (Huang et al. 1992). The resulting plasmids were transformed into $E$. coli strain S17-1 and introduced into $S$. meliloti $\Delta 1 \mathrm{~A}$ by biparental mating. The $t s \mathrm{mu}-$ tants were identified by replica plating on $\mathrm{MMNH}_{4}$ media with tetracycline at $10 \mu \mathrm{g} / \mathrm{ml}$ and growing the duplicate plates at 20 , 25 , and $30^{\circ} \mathrm{C}$. Five isolates that grew at 20 and $25^{\circ} \mathrm{C}$ but not at $30^{\circ} \mathrm{C}$ were isolated. Two of these, S. meliloti $\Delta 1 \mathrm{~A}(\mathrm{pMK} 511)$ and $S$. meliloti $\Delta 1 \mathrm{~A}(\mathrm{pMK} 512)$, were used for further study. pCPP30 can replicate in S. meliloti; therefore, pMK511 and pMK512 were maintained extrachromosomally as independently replicating plasmids. We confirmed that the $t s$ glutamate requirement was conferred by pMK511 and pMK512 plasmids by isolating plasmid DNA from $S$. meliloti $\Delta 1 \mathrm{~A}(\mathrm{pMK} 511)$ and $S$. meliloti $\Delta 1 \mathrm{~A}(\mathrm{pMK} 512)$, reintroducing this DNA into $S$. meliloti $\triangle 1 \mathrm{~A}$, and confirming the growth phenotype. DNA sequencing of the $1.8-\mathrm{kb}$ insert in pMK511 revealed three changes from the original sequence, a silent $\mathrm{G} \rightarrow \mathrm{C}$ substitution at position 1049 , an $A \rightarrow G$ substitution at a position 1050 that resulted in an N229D mutation, and a $\mathrm{G} \rightarrow \mathrm{A}$ substitution in the untranscribed region at position -358 upstream from the start codon.

Both $S$. meliloti $\Delta 1 \mathrm{~A}(\mathrm{pMK} 511)$ and $S$. meliloti $\triangle 1 \mathrm{~A}(\mathrm{pMK} 512)$ grew in liquid $\mathrm{MMNH}_{4}$ at $20^{\circ} \mathrm{C}$. CS activities in mutants grown under different conditions are shown in Table 2. In $S$. meliloti, arabinose is converted to $\alpha$-ketoglutarate and can relieve the glutamate auxotrophy of gltA and icd mutants (McDermott and Kahn 1992; Mortimer et al. 1999). As expected, the $t s$ mutants did not grow in unsupplemented $\mathrm{MMNH}_{4}$ at $30^{\circ} \mathrm{C}$ but did grow at this temperature when arabi- nose was added at optimum (0.25\%) and limiting (0.0125\%) concentrations. CS activity was very low in all mutant cultures at $30^{\circ} \mathrm{C}$. At $20^{\circ} \mathrm{C}$, the addition of $0.25 \%$ arabinose significantly decreased CS activity, but there was no reduction in activity at $0.0125 \%$ arabinose. This effect of arabinose also was seen in wild-type $S$. meliloti Rm104A14, suggesting a link between the production of $\alpha$-ketoglutarate during arabinose catabolism and the control of CS. Reduced CS activity also was observed when cultures of Rm104A14 were grown in the presence of $0.25 \%$ arabinose but not at $0.0125 \%$ (Table 2 ).

When $S$. meliloti $\Delta 1 \mathrm{~A}(\mathrm{pMK} 511)$ was grown to late exponential phase in liquid $\mathrm{MMNH}_{4}$ at $20^{\circ} \mathrm{C}$, then transferred to $30^{\circ} \mathrm{C}$, growth continued for up to $12 \mathrm{~h}$ and total CS activity in the culture did not change (data not shown). After $12 \mathrm{~h}$, bacterial growth ceased and CS activity decreased to below a detectable level. In contrast, control cultures of S. meliloti Rm104A14 and MK506 grew well at $30^{\circ} \mathrm{C}$ and maintained the same CS specific activity as cultures grown at $20^{\circ} \mathrm{C}$. When CS activity from the $t s$ mutants grown at $20^{\circ} \mathrm{C}$ was assayed at $30^{\circ} \mathrm{C}$, it increased by $5.8 \%$ for $S$. meliloti $\Delta 1 \mathrm{~A}(\mathrm{pMK} 511)$ and $20 \%$ for $S$. meliloti $\Delta 1 \mathrm{~A}(\mathrm{pMK} 512)$. These results suggest that the CS enzyme in the ts mutant was stable at $30^{\circ} \mathrm{C}$ but that some other factor affecting enzyme activity, such as assembly of the CS multimer, was defective at the high temperature.

\section{Nodulation by partial-function mutants.}

Alfalfa plants were inoculated with mutant rhizobia to study the dependence of symbiotic nitrogen fixation activity on CS activity. A constant root temperature of $20^{\circ} \mathrm{C}$ was established by placing the boxes containing the plant roots into a temperature-controlled water bath. The shoot was exposed to air in a growth chamber maintained at $25^{\circ} \mathrm{C}$ and constant light. In pre-

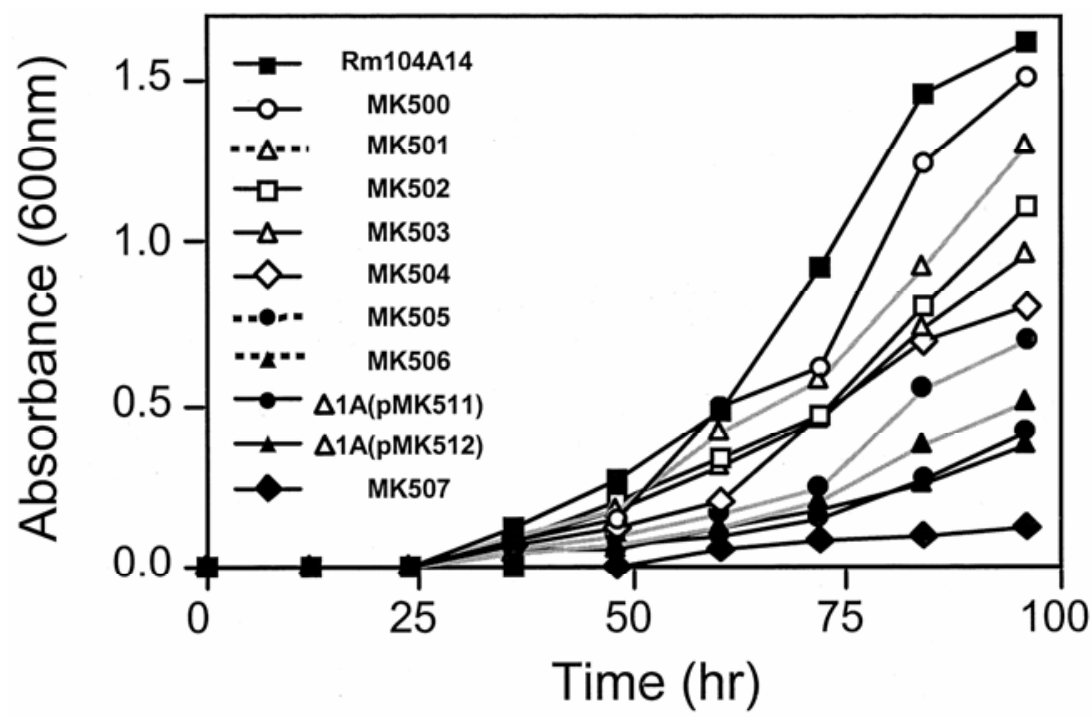

Fig. 2. Growth of citrate synthase mutants. Growth curves of partial function and temperature sensitive mutants in unsupplemented minimal mannitol ammonia medium at $20^{\circ} \mathrm{C}$. From the top (at $96 \mathrm{~h}$ ), the strains are Rm104A14, MK500-MK506, $\Delta 1 \mathrm{~A}(\mathrm{pMK} 511), \Delta 1 \mathrm{~A}(\mathrm{pMK} 512)$, and MK507.

Table 2. Citrate synthase activities of Sinorhizobium meliloti temperature-sensitive mutants ${ }^{\mathrm{a}}$

\begin{tabular}{|c|c|c|c|c|c|c|}
\hline \multirow[b]{3}{*}{ Strain } & \multicolumn{6}{|c|}{ Nodule temperature } \\
\hline & \multicolumn{3}{|c|}{$20^{\circ} \mathrm{C}$} & \multicolumn{3}{|c|}{$30^{\circ} \mathrm{C}$} \\
\hline & No arabinose & $0.25 \%$ arabinose & $0.0125 \%$ arabinose & No arabinose & $0.25 \%$ arabinose & $0.0125 \%$ arabinose \\
\hline$\Delta 1 \mathrm{~A}(\mathrm{pMK} 511)$ & $9.7 \pm 0.1$ & $2.3 \pm 0.1$ & $9.8 \pm 0.3$ & NG & $0.6 \pm 0.1$ & $0.6 \pm 0.1$ \\
\hline$\Delta 1 \mathrm{~A}(\mathrm{pMK} 512)$ & $9.2 \pm 0.2$ & $3.1 \pm 0.1$ & $9.1 \pm 0.2$ & NG & $0.7 \pm 0.1$ & $0.6 \pm 0.1$ \\
\hline 104A14 & $336.9 \pm 6.1$ & $47.6 \pm 0.0$ & $336.9 \pm 6.1$ & ND & ND & ND \\
\hline
\end{tabular}

${ }^{\mathrm{a}}$ S. meliloti $\Delta 1 \mathrm{~A}(\mathrm{pMK} 511)$ and S. meliloti $\Delta 1 \mathrm{~A}(\mathrm{pMK} 512)$ were grown at 20 and $30^{\circ} \mathrm{C}$ without supplements or in the presence of 0.25 or $0.0125 \%$ arabinose, as indicated. Enzymatic activity is expressed as nmole $/ \mathrm{min} / \mathrm{mg}$ protein. $\mathrm{NG}=$ no growth and $\mathrm{ND}=$ not determined. 
liminary nodulation experiments conducted at 20 and $25^{\circ} \mathrm{C}$, we found that the reduced root temperature was needed to minimize emergence of revertant bacterial strains with higher CS activities (data not shown). After 5 to 6 weeks of growth, nodules were collected and assayed for nitrogenase activity. To determine whether there were any revertants, we prepared bacteroids from the nodules and also isolated viable bacteria from crushed nodules on $\mathrm{MMNH}_{4}$. CS activity in extracts from bacteroids and bacterial isolates had the same activity as the mutants used for the inoculation (data not shown). This indicates that revertants were not common and probably were absent from the nodules.

Plants nodulated with a mutant that had only $7 \%$ of wildtype CS activity were fully effective, as measured by plant growth and nitrogenase activity (Fig. 3). Three independent mutants with about $3 \%$ of wild-type activity produced normallooking nodules that reduced acetylene at approximately $20 \%$ of the wild-type rate but did not stimulate plant growth. Strain MK507, which had only $0.3 \%$ of wild-type CS activity, produced white nodules that were unable to reduce acetylene.

The morphology of nodules produced by the mutants was compared with those made by Rm104A14 using light microscopy. There were no obvious morphological differences between nodules induced by $S$. meliloti Rm104A14 and mutants MK504 and MK506 (Fig 4)—all had enlarged plant cells filled with bacteroids adjacent to empty cells containing starch granules. Nodules formed by S. meliloti $\Delta 1 \mathrm{~A}(\mathrm{pMK} 511)$, which had lower CS activity (Table 1), had somewhat fewer enlarged, bacteroid-filled cells and more smaller cells with starch granules than other mutants and S. meliloti Rm104A14.

It is generally accepted that dicarboxylic acids are a major source of carbon and energy for the bacteroids, and the TCA cycle is a plausible way to metabolize these (Dunn 1998; Kahn et al. 1998). Results with null mutants in TCA cycle genes support this idea, at least to the extent of saying that some activity of the various enzymes is essential for a functional symbiosis. We were surprised to find that mutants with very low CS activity were as competent as the wild type in nodule formation and nitrogen fixation, because lower CS activity in Rhizobium tropici does affect nodulation (Hernandez-Lucas et al. 1995). Our results suggest that the energy flow to nitrogenase was not impaired until CS activity was less than $7 \%$ of normal and that catabolism through the TCA cycle sufficient to sustain nitrogenase activity can be very low. It is possible that catabolism in these mutants was redirected to other pathways that do not involve CS (Driscoll and Finan 1997; Dunn 1998).
Nodulation by $t$ s mutants.

The $t s$ mutants $S$. meliloti $\Delta 1 \mathrm{~A}(\mathrm{pMK} 511)$ and $S$. meliloti $\Delta 1 \mathrm{~A}(\mathrm{pMK} 512)$ successfully nodulate alfalfa and produce nitrogen-fixing nodules, indicating that the gltA mutation they contain does not block nodule development. In nodules formed by these mutants, we were able to shut down bacteroid CS by increasing the root and nodule temperature and determine what effect the subtraction of CS had on nitrogen fixation and bacteroid stability. Alfalfa roots inoculated with $S$. meliloti $\Delta 1 \mathrm{~A}(\mathrm{pMK} 511)$ and $S$. meliloti $\Delta 1 \mathrm{~A}(\mathrm{pMK} 512)$ were grown at $20^{\circ} \mathrm{C}$ for 35 days, then transferred to $30^{\circ} \mathrm{C}$. Nodules were collected immediately (" 0 " time) and after 2, 4, 6, 9, 12, and 15 days and assayed for nitrogenase (acetylene reduction) activity. Alfalfa plants inoculated with $S$. meliloti Rm104A14 and grown in the same way were used as controls. Additional control plants inoculated with $S$. meliloti $\Delta 1 \mathrm{~A}(\mathrm{pMK} 511)$ and $S$. meliloti $\Delta 1 \mathrm{~A}(\mathrm{pMK} 512)$ and plants inoculated with $S$. meliloti $\mathrm{Rm} 104 \mathrm{~A} 14$ were grown at $20^{\circ} \mathrm{C}$ only. The CS activities in bacteroids and in bacteria isolated from crushed nodules and grown on $\mathrm{MMNH}_{4}$ medium were measured to evaluate possible reversion. We found no evidence for reversion because the activity in all isolates was in the same range as the activity in bacteria used for the inoculum.

Nitrogenase activity in nodules isolated from $t s$ mutants decreased rapidly after transfer to $30^{\circ} \mathrm{C}$ and remained very low, at the background noise level, until the end of the 15-day experiment (Fig. 5, upper). Some decrease in nitrogenase activity after the temperature shift also was seen in nodules formed by the wild-type bacteria, but this stabilized after 4 days. The weight of plants inoculated with $t s$ mutants did not change over the course of the temperature shift, but the weight of plants inoculated with the wild-type increased by approximately $20 \%$ (Fig. 5, lower). Nitrogenase activities in control plants nodulated by the mutants but held at $20^{\circ} \mathrm{C}$ were assayed after 15 days and had not changed for $S$. meliloti $\Delta 1 \mathrm{~A}(\mathrm{pMK} 511)$ and increased approximately $38 \%$ for $S$. meliloti $\Delta 1 \mathrm{~A}(\mathrm{pMK} 512)$ (data not shown). The weight of these plants increased $30 \%$ for $S$. meliloti $\Delta 1 \mathrm{~A}(\mathrm{pMK} 511)$ and $15 \%$ for $S$. meliloti $\Delta 1 \mathrm{~A}(\mathrm{pMK} 512)$. Nitrogenase activity in control plants inoculated with $S$. meliloti Rm104A14 and held at $20^{\circ} \mathrm{C}$ for 15 days increased by $28 \%$ and their weight by $35 \%$.

To determine the effect of increased temperature on bacteroid CS, we isolated bacteroids from nodules and assayed for the activity. Despite the relatively small size and numbers of nodules, it was possible to isolate bacteroids from nodules collected from plants nodulated by $S$. meliloti $\Delta 1 \mathrm{~A}(\mathrm{pMK} 511)$ in

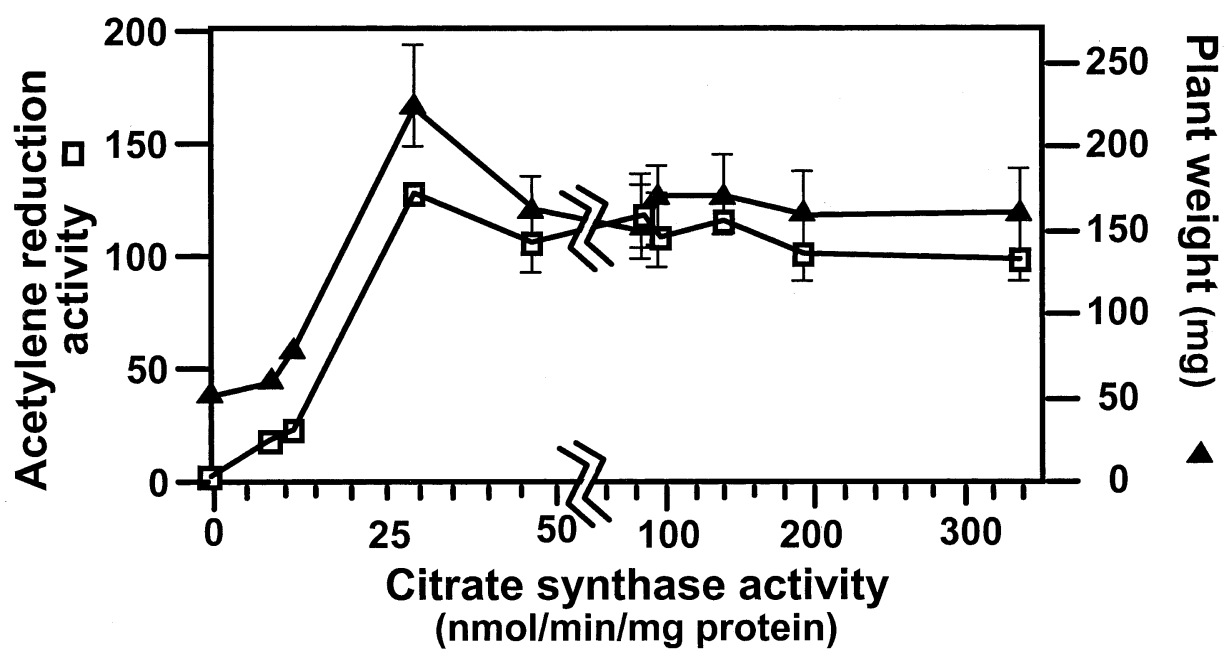

Fig. 3. Symbiotic performance of citrate synthase mutants. Nitrogenase (acetylene reduction) activity (nmol/min/g of nodules) (open squares) and plant wet weight (mg) (solid triangles) are plotted as a function of citrate synthase activity (nmol/min/mg of protein) in the mutants. 
the first 2 days after the temperature shift. CS activities in bacteroids from plants grown at $20^{\circ} \mathrm{C}$ and from plants incubated at $30^{\circ} \mathrm{C}$ for 2 days were near the CS activity of approximately 10 nmole $/ \mathrm{min} / \mathrm{mg}$ of protein normally found for this strain in freeliving culture. At later times, the yield of bacteroids from plants incubated at $30^{\circ} \mathrm{C}$ decreased dramatically and we were unable to isolate sufficient quantities for CS activity assays. In addition, light microscopy indicated that the ratio of impurities to bacteroids had increased, making any meaningful enzyme assays impossible. CS activities in bacteroids from plants grown at $20^{\circ} \mathrm{C}$ for longer than 2 days remained at the same level. In contrast, we were able to isolate bacteroids from nodules from plants inoculated with MK506 and S. meliloti Rm104A14 without a reduction of yield after transfer to $30^{\circ} \mathrm{C}$. CS activity in bacteroids from plants inoculated with MK506 was $16.6 \pm 0.21 \mathrm{nmole} / \mathrm{min} / \mathrm{mg}$ of protein, in the same range as the activity in bacteria grown in liquid cultures. CS activity decreased moderately after transfer of the plants to $30^{\circ} \mathrm{C}$ ( 2 days at $30^{\circ} \mathrm{C}, 18.2 \pm 1.4 \mathrm{nmole} / \mathrm{min} / \mathrm{mg}$ if protein; 4 days, $13.3 \pm$ 0.3 ; and 6 days, $12.9 \pm 0.4$ ). Bacteroids from plants inoculated with $S$. meliloti $\mathrm{Rm} 104 \mathrm{~A} 14$ and grown at $20^{\circ} \mathrm{C}$ had CS activity of $264.46 \pm 2.57 \mathrm{nmole} / \mathrm{min} / \mathrm{mg}$ of protein, lower than in bacteria grown in liquid cultures $(336.9 \pm 6.1 \mathrm{nmole} / \mathrm{min} / \mathrm{mg}$ of protein). The activity decreased slightly after plants were transferred to $30^{\circ} \mathrm{C}$. (2 days at $30^{\circ} \mathrm{C}, 248.6 \pm 10.8 \mathrm{nmole} / \mathrm{min} / \mathrm{mg}$ of protein; 4 days, $205.1 \pm 7.2$; and 6 days, $221.87 \pm 8.4$ ).

The loss of bacteroids in nodules induced by $S$. meliloti $\Delta 1 \mathrm{~A}(\mathrm{pMK} 511)$ was examined further by light microscopy (Fig 4). Sections were prepared from nodules collected from plants inoculated with $S$. meliloti $\Delta 1 \mathrm{~A}(\mathrm{pMK} 511)$ and incubated at $30^{\circ} \mathrm{C}$ for up to 6 days. Nodules from plants grown at $20^{\circ} \mathrm{C}$ had a morphology typical of the wild type, with easily distinguishable meristematic, nitrogen fixation, and senescence zones (Debelle et al. 1986). Cells in the nitrogen fixation zone were greatly enlarged and tightly packed with bacteroids (Fig. 4D). After transfer to $30^{\circ} \mathrm{C}$, we observed a number of morphological changes that coincided with the decrease in nitrogen fixation rates and resembled changes seen during nodule senes- cence. Most apparent was a decreased number of bacteroids in infected cells, first seen in nodules after 2 days of incubation at $30^{\circ} \mathrm{C}$ (Fig. 4E) but which became increasingly obvious after 4 and 6 days of incubation at $30^{\circ} \mathrm{C}$ (Fig. $4 \mathrm{~F}$ and $\left.\mathrm{G}\right)$. In these nodules, most of the remaining bacteroids were near the periphery of the infected cells and the center was filled with large vacuoles and accumulated amorphous material. There was an increase in the proportion of bacteroid-free cells partially filled with starch granules. Starch granules also became visible in increasing numbers of cells with bacteroids. Granules were located on the cell periphery, often adjacent to the cellular membrane.

Differences in the appearance of the $S$. meliloti $\Delta 1 \mathrm{~A}$ (pMK511) bacteroids before and after the temperature shift also can be seen using electron microscopy (compare Fig. 6A with Fig. 6B). After the temperature shift, the bacteroids were smaller and more irregular and contained more prominent inclusions than they did prior to the shift. These inclusions might be poly $\beta$-hydroxybutyrate or glycogen deposits that result from the bacteroids' inability to route carbon through the TCA cycle. The peribacteroid membranes surrounding bacteroids in the nitrogen-fixation zone were more separated from the bacteroids (Fig. 6B). Figure 6B was photographed in one of the peripheral plant cell regions that contained bacteroids and does not show the large amount of membranous material not associated with bacteroids that was more prominent in the interior regions of the infected plant cells. This material, which we speculate was debris resulting from bacteroid degradation, was not seen in sections of infected plant cells from nodules isolated before the temperature shift (data not shown).

This dramatic loss of bacteroids may be related to the loss of protection against plant defense mechanisms. As discussed previously, rhizobia produce succinylated EPSI, and this is thought to act as a suppressor of the plant defense system (Debelle et al. 1986; Niehaus et al. 1993). Another possibility is that bacteroid lysis occurred due to an inability to carry out metabolism needed to raise the $\mathrm{pH}$ in the symbiosome, allowing plant hydrolases within the membrane to become more active (Mellor 1989).
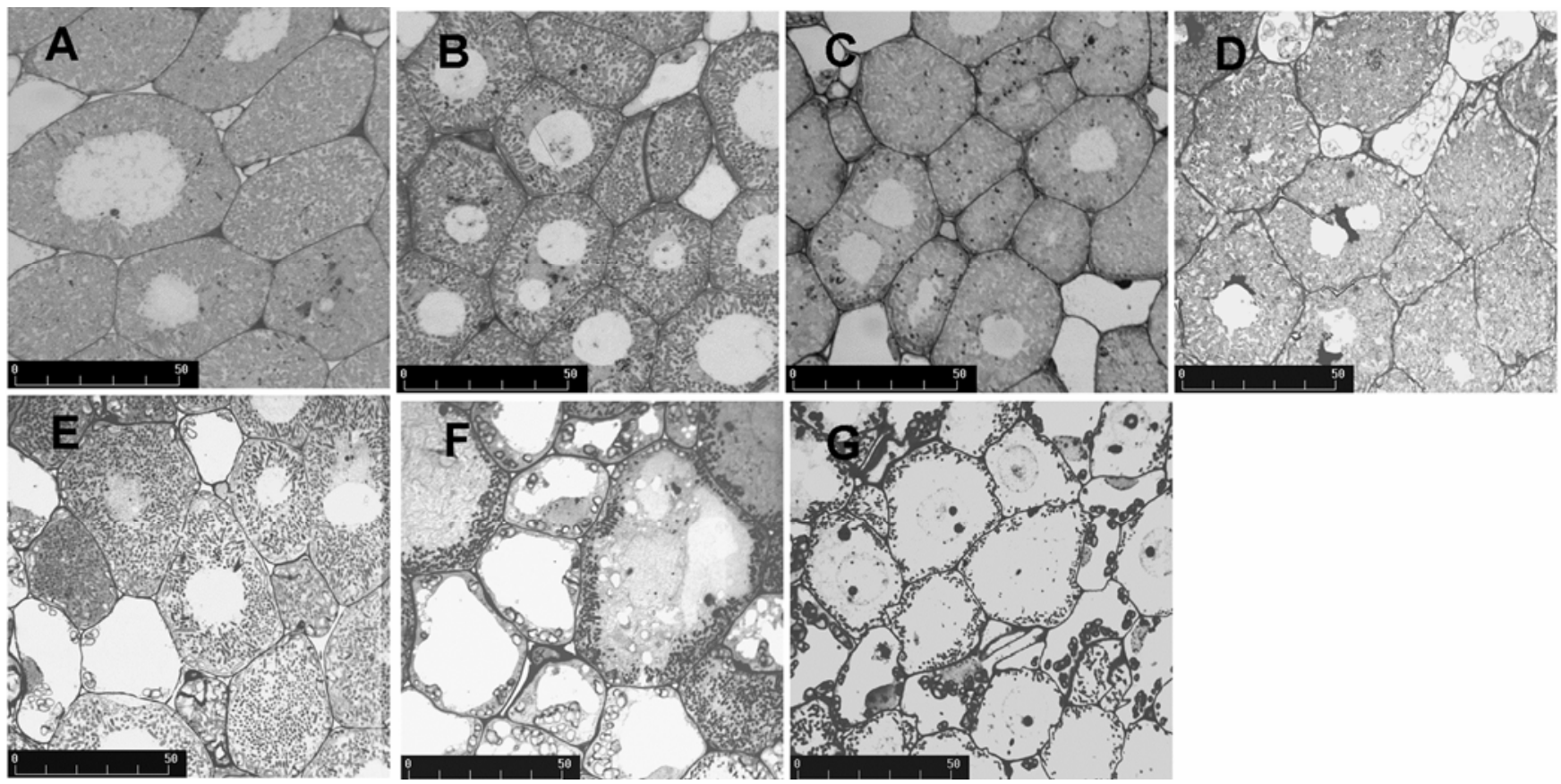

Fig. 4. Structure of root nodules formed by citrate synthase mutants. Nodules induced by the wild-type and mutant rhizobia and grown at various temperatures were fixed and sectioned as described in the text. A, Sinorhizobium meliloti Rm104A14; B, MK504 grown at $20^{\circ} \mathrm{C} ; \mathbf{C}, \mathrm{MK}^{\circ} 06$ grown at $20^{\circ} \mathrm{C}$; D, S. meliloti $\Delta 1 \mathrm{~A}(\mathrm{pMK} 511)$ grown at $20^{\circ} \mathrm{C} ; \mathbf{E}$, S. meliloti $\Delta 1 \mathrm{~A}(\mathrm{pMK} 511)$ grown at $30^{\circ} \mathrm{C}$ for 2 days; F. S. meliloti $\Delta 1 \mathrm{~A}(\mathrm{pMK} 511)$ grown at $30^{\circ} \mathrm{C}$ for 4 days; and $\mathbf{G}, S$. meliloti $\Delta 1 \mathrm{~A}(\mathrm{pMK} 511)$ grown at $30^{\circ} \mathrm{C}$ for 6 days. 
Using point mutations in the bacterial gltA gene to investigate the role of CS in symbiosis leads to a better appreciation of the role of this TCA cycle enzyme in symbiosis. Although previous work had shown that null mutants of gltA formed empty and ineffective nodules (Mortimer et al. 1999), the current work shows that a relatively low CS activity was needed for full effectiveness, even though CS mutants with moderate defects had lower growth rates in vitro. Thus, although CS appeared to be a limiting activity in free-living bacteria, CS was not normally limiting for nodule nitrogen fixation. This implies that a high flux through the TCA cycle may not be critical for nitrogen fixation. On the other hand, experiments with CS $t s$ mutants showed that some CS activity is needed in mature nodules to maintain bacteroid integrity and that removing CS activity via a temperature shift converts an effective nodule into an empty nodule. This implies that CS is needed throughout nodule development and not simply to make a factor used in the early stages of plant cell invasion.

Results with other rhizobia also indicate that lower activity sufficient to reduce the free-living growth rate may not impair symbiotic function, though the results were not as systematic in exploring a range of enzyme activity as this study. So, for example, inactivation of an aconitase in Bradyrhizobium japonicum decreases enzyme activity by $70 \%$ and inhibits freeliving growth but leads to nodules with normal fixation (Thony-Meyer and Kunzler 1996). A B. japonicum mutant lacking 2-oxoglutarate dehydrogenase has some free-living and nodule development problems but the specific activity of bacteroids is near normal, a capability that was associated with a 2-oxoglutarate decarboxylase activity that bypassed 2-oxoglutarate dehydrogenase (Green et al. 2000). In R. tropici there are two gltA genes, one on the chromosome and the other on a symbiotic plasmid. Loss of either gene lowers nodulation abil- ity and loss of both results in ineffective, empty nodules (Hernandez-Lucas et al. 1995).

Bacterial null mutations can result in the development of ineffective nodules or even lead to the lack of nodulation altogether. This can indicate a role for the affected gene in the host-bacterial interaction but, by blocking development, it also can prevent a more detailed examination of the need for the gene product at later stages of development. In this work, using $t s$ CS mutants allowed functional root nodules to develop and the subsequent demonstration that citrate synthase was needed for continuing operation of this root nodule. The methods used here should be useful in analysis of other genes where null mutations lead to an ineffective phenotype. For enzymes that are connected to several different metabolic pathways, the ability to introduce a graded series of mutants also may be useful in distinguishing which of
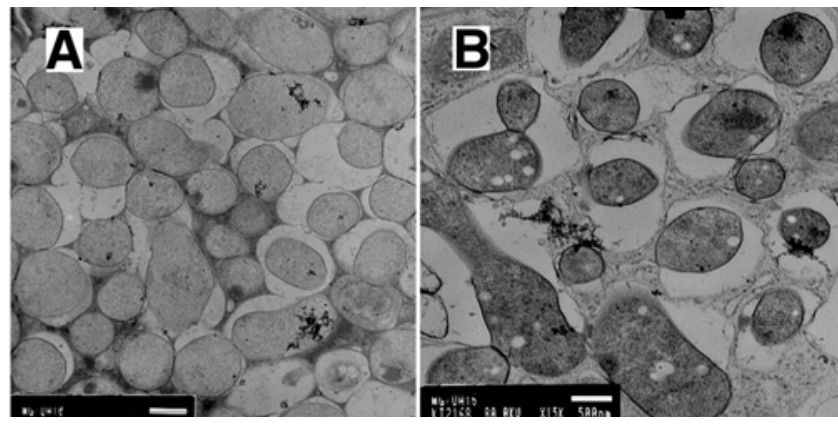

Fig. 6. Bacteroids before and after a temperature shift. Electron micrograph of A, Sinorhizobium meliloti $\Delta 1 \mathrm{~A}(\mathrm{pMK} 511)$ bacteroids from plants grown with a root temperature of $20^{\circ} \mathrm{C}$ and $\mathbf{B}$, S. meliloti $\Delta 1 \mathrm{~A}(\mathrm{pMK} 511)$ bacteroids from plants grown with a root temperature of $20^{\circ} \mathrm{C}$, then shifted to a root temperature of $30^{\circ} \mathrm{C}$ for 6 days. $\mathrm{Bar}=500 \mathrm{~nm}$.

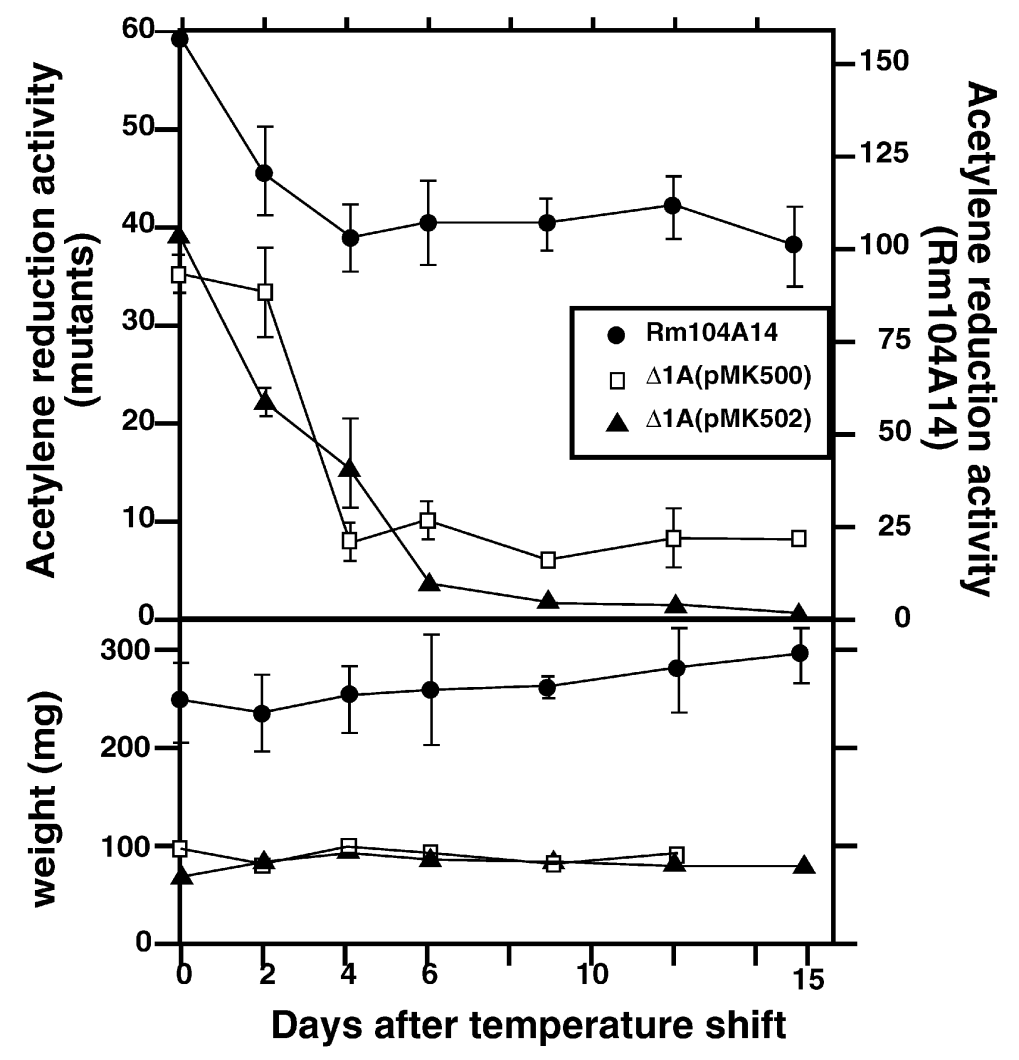

Fig. 5. Symbiotic performance of root nodules following a temperature shift. Reduction of nitrogenase activity in nodules produced by Sinorhizobium meliloti $\Delta 1 \mathrm{~A}(\mathrm{pMK} 511)$, S. meliloti $\Delta 1 \mathrm{~A}(\mathrm{pMK} 512)$, and $S$. meliloti Rm104A14 after transfer from 20 to $30^{\circ} \mathrm{C}$. X axis: days after transfer to $30^{\circ} \mathrm{C}$. Upper graph, left Y axis: nitrogenase (acetylene reduction) activity (nmol/min/g of nodules) in S. meliloti $\Delta 1 \mathrm{~A}(\mathrm{pMK} 511)$ (open squares), S. meliloti $\Delta 1 \mathrm{~A}(\mathrm{pMK} 512)$ (solid triangles); right Y axis: nitrogenase activity (nmol/min/g of nodules) in S. meliloti Rm104A14 (solid circles). Lower graph: wet weight of plants (mg). 
these pathways is important at what stages through more detailed physiological analysis of mutant nodules.

\section{MATERIALS AND METHODS}

\section{DNA manipulations and bacterial strains.}

DNA manipulations were carried out according to standard procedures (Sambrook et al. 1989) or as recommended by manufacturers. Plasmid DNA was conjugated into rhizobia using E. coli $\mathrm{S} 17-1$ as a donor strain (Quandt and Hynes 1993). DNA sequencing was carried out by the DyeDeoxy terminator cycle protocol using synthetic primers synthesized by Invitrogen. Sequencing reactions were analyzed on an Applied Biosystems 373 DNA Sequencer at the Washington State University Laboratory for Bioanalysis and Biotechnology. Bacterial strains and media have been described previously (Mortimer et al. 1999; Somerville and Kahn 1983). The E. coli gltA mutant MOB154 (Wood et al. 1983) was grown on M9 medium supplemented with glutamate at $5 \mathrm{mg} / \mathrm{ml}$, uracil at $50 \mu \mathrm{g} / \mathrm{ml}$, and thiamine at $2 \mu \mathrm{g} / \mathrm{ml}$.

\section{Construction of a gltA deletion mutant.}

To create a strain in which the mutated copy of gltA would not be able to recombine with any other gltA sequence, we constructed $S$. meliloti $\Delta 1 \mathrm{~A}$, a derivative of $S$. meliloti Rm104A14 in which the CS ORF was deleted. In a modification of the procedure described by Quandt and Hynes (1993), we subcloned a 5.6-kb fragment containing the $S$. meliloti Rm104A14 gltA gene into pUC18. A 7.3-kb fragment that contained $5^{\prime}$ and $3^{\prime}$ regions flanking gltA and pUC18 DNA was amplified from this construct by PCR with primers: $\alpha-\mathrm{v}\left(5^{\prime}\right.$ TAT TCT TAA GGG GAC CCT CCG TGT TGT G $3^{\prime}$ ) and $\beta$-d (5' TGA GCT TAA GTG AAC GGC GAA CGC AG 3') (Fig. $1)$. Both primers have a 10 -bp $5^{\prime}$ overhang that contains an AflII restriction site (underlined). Following PCR amplification, this fragment was cut with $A f l I I$ and religated, resulting in plasmid pJPA21. A 4.7-kb PstI-SacI fragment from pJPA21, which contains the flanking regions of the $S$. meliloti Rm104A14 gltA gene, was subcloned into plasmid pJPA22 to give plasmid pJPA23. pJPA22 is a derivative of pJQ200KS (Quandt and Hynes 1993) that has a 2.7-kb tetracycline resistance $B g l I I$ cassette from Tn10 inserted into the BglII site within the pJQ200KS gentamicin gene.

pJPA23 was conjugated into $S$. meliloti Rm104A14. The integration of pJPA23 into the $S$. meliloti Rm104A14 chromosome probably occurred within one of the gltA ORF flanking regions. Single recombinants, which were tetracycline resistant, were subcultured on $\mathrm{MMNH}_{4}$ agar supplemented with $0.25 \%$ arabinose and $5 \%$ sucrose. Only rhizobia that lose the $s a c B$ gene in pJPA22 can grow on this media, and these colonies were checked for the loss of tetracycline resistance and an arabinose requirement. The loss of $s a c B$ probably occurred by the formation of a loop between sequences flanking the CS ORF carried on pJPA23 and the homologous sequences of the CS gene on the $S$. meliloti Rm104A14 chromosome. This second recombination would delete the gltA ORF, leaving only the flanking regions. We confirmed this structure in $S$. meliloti $\Delta 1 \mathrm{~A}$ by amplifying the resulting chromosomal DNA with primers CS1 and CS2. This produced a 0.6-kb fragment, which is the length of flanking regions.

\section{Localized random PCR mutagenesis.}

Localized random PCR mutagenesis was performed essentially as described by Lerner and associates (1995). A $1.8-\mathrm{kb}$ gltA fragment was amplified with Taq polymerase using CS1 (5'GAG AGC TGC AGT TCG GCG GGG GGC GGA G 3') and CS2 (5' GAG ACG AGC TCG GGT CAA GCC AAA
GGA T $3^{\prime}$ ) primers. The primers have 11-bp 5' overhangs that contain PstI (CS1) and SacI (CS2) restriction sites (underlined). The $25-\mu \mathrm{l}$ reaction mixture contained $2 \mathrm{U}$ of Taq polymerase (Fisher, Pittsburgh), $60 \mathrm{mM}$ Tris- $\mathrm{SO}_{4}\left(\mathrm{pH} 9.1\right.$ at $25^{\circ} \mathrm{C}$ ), $18 \mathrm{mM}\left(\mathrm{NH}_{4}\right)_{2} \mathrm{SO}_{4}, 2 \mathrm{mM} \mathrm{MgSO}{ }_{4}, 200 \mathrm{nM}$ of each primer, $200 \mu \mathrm{M}$ of each dNTP and $200 \mu \mathrm{M}$ dITP. The reaction was amplified for 30 cycles of $60 \mathrm{~s}$ at $94^{\circ} \mathrm{C}, 60 \mathrm{~s}$ at $55^{\circ} \mathrm{C}$, and $120 \mathrm{~s}$ at $72^{\circ} \mathrm{C}$. The product was purified with Prep-A-Gene DNA Purification Kit (Bio-Rad, Hercules, CA, U.S.A.), digested with PstI and SacI, and cloned into the pJPA22 suicide vector.

\section{DNA shuffling.}

DNA shuffling was carried out by modifying a procedure described previously (Zhao and Arnold 1997). A 1.8-kb fragment of $S$. meliloti gltA cloned into the pBluescript $\mathrm{SK}^{-}$vector was used as the substrate. This construct was digested with DNAse I (Sigma, St. Louis) to produce fragments smaller than 50 bases, as determined by electrophoresis on a $2 \%$ agarose gel. Fragments (100 ng) were extended with Taq polymerase for 40 cycles in the buffer described above using the following cycling conditions: $60 \mathrm{~s}$ at $94^{\circ} \mathrm{C}, 60 \mathrm{~s}$ at $55^{\circ} \mathrm{C}$, and $125 \mathrm{~s}$ at $72^{\circ} \mathrm{C}$. After 40 cycles, the reaction was diluted $1: 1$ with fresh reaction mix and extended for a further 40 cycles. This dilution was repeated one more time to give a total of 120 cycles. The $1.8-\mathrm{kb}$ gltA fragment then was recovered by using the CS1 and CS2 primers to amplify $1 \mu \mathrm{l}$ of the shuffled product.

\section{Plant growth.}

Plants were grown with constant illumination in open Magenta boxes in a mixture of sterile sand and LECA Clay Pellets (ECO Enterprises, Bremerton, WA, U.S.A.) and watered with nitrogen-free plant nutrient solution (Mortimer et al. 1999). Room temperature was maintained at $26^{\circ} \mathrm{C}$. Root temperature was controlled by placing the plant boxes into water baths cooled or warmed by circulating water through copper tubing immersed in the bath.

\section{Bacteroid purification and enzyme assays.}

Bacteroids were purified from nodules by the method described by Brewin and associates (1985). CS was assayed by the previously described procedure (Srere 1969). Acetylene reduction assays to measure nitrogenase activity were carried out as described by McDermott and Kahn (1992).

\section{Microscopy.}

Nodules were prepared for sectioning by a standard procedure that involved fixation with $2.5 \%$ glutaraldehyde $/ 2 \%$ paraformaldehyde, postfixation with $1 \% \mathrm{OsO}_{4}$, then dehydration in an acetone series followed by embedding in Spurr's resin (Hayat 2000). Each 350-nm section was cut, mounted on glass microscope slides, and stained with Stevenel's blue stain. For electron microscopy, gray to silver sections (60 to $120 \mathrm{~nm}$ ) were cut from the same blocks and stained with lead citrate (Hayat 2000).

\section{ACKNOWLEDGMENTS}

This work was supported by the Washington State University Agriculture Research Center and grants DE-FG06-93ER20119 and DE-FG0396ER20225 from the United States Department of Energy-Energy Biosciences Program. We thank M. Mortimer and C. Pruiett for help with the initial complementation experiments, and C. Davitt and V. Lynch-Holm for help with the microscopy.

\section{LITERATURE CITED}

Battisti, L., Lara, J. C., and Leigh, J. A. 1992. Specific oligosaccharide form of the Rhizobium meliloti exopolysaccharide promotes nodule invasion in alfalfa. Proc. Natl. Acad. Sci. U.S.A. 89:5625-5629. 
Brewin, N. J., Robertson, J. G., Wood, E. A., Wells, B., Larkins, A. P., Galfre, G., and Butcher, G. W. 1985. Monoclonal antibodies to antigens in the peribacteroid membrane from Rhizobium-induced root nodules of pea cross-react with plasma membranes and Golgi bodies. EMBO (Eur. Mol. Biol. Organ.) J. 4:605-611.

Broughton, W. J., Jabbouri, S., and Perret, X. 2000. Keys to symbiotic harmony. J. Bacteriol. 182:5641-5210.

Debelle, F., Rosenberg, C., Vasse, J., Maillet, F., Martinez, E., Denarie, J., and Truchet, G. 1986. Assignment of symbiotic developmental phenotypes to common and specific nodulation (nod) genetic loci of Rhizobium meliloti. J. Bacteriol. 168:1075-1086.

Driscoll, B. T., and Finan, T. M. 1997. Properties of NAD+ and NADP+ dependent malic enzymes of Rhizobium (Sinorhizobium) meliloti and differential expression of their genes in nitrogen-fixing bacteroids. Microbiology 143:489-498.

Dunn, M. F. 1998. Tricarboxylic acid cycle and anaplerotic enzymes in rhizobia. FEMS (Fed. Eur. Microbiol. Soc.) Microbiol. Rev. 22:105-123.

Green, L. S., Li, Y., Emerich, D. W., Bergersen, F. J., and Day, D. A. 2000 Catabolism of alpha-ketoglutarate by a sucA mutant of Bradyrhizobium japonicum: Evidence for an alternative tricarboxylic acid cycle. J. Bacteriol. 182:2838-2844.

Hayat, M. A. 2000. Principles and techniques of electron microscopy. Biological applications. Cambridge University Press, Cambridge.

Hernandez-Lucas, I., Pardo, M. A., Segovia, L., Miranda, J., and MartinezRomero, E. 1995. Rhizobium tropici chromosomal citrate synthase gene. Appl. Environ. Microbiol. 61:3992-3997.

Hooke, A. M. 1994. Temperature-sensitive mutants of bacterial pathogens: Isolation and use to determine host clearance and in vivo replication rates. Methods Enzymol. 235:448-457.

Huang, H. C., He, S. Y. Bauer, D. W., and Collmer, A. 1992. The Pseudomonas syringae pv. syringae $61 \mathrm{hrpH}$ product, an envelope protein required for elicitation of the hypersensitive response in plants. J. Bacteriol. 174:6878-6885.

Kahn, M. L., McDermott, T. R., and Udvardi, M. K. 1998. Carbon and nitrogen metabolism in rhizobia. Pages 461-485 in: The Rhizobiacae: Molecular Biology of Model Plant-Associated Bacteria. H. P. Spaink, A. Kondorosi, and P. J. J. Hooykaas, eds. Kluwer Academic, Dordrecht, The Netherlands.

Kistner, C., and Parniske, M. 2002. Evolution of signal transduction in intracellular symbiosis. Trends Plant Sci. 7:511-518

Krishnan, H. B., Kim, W. S., Sun-Hyung, J., Kim, K. Y., and Jiang, G. 2003. Citrate synthase mutants of Sinorhizobium fredii USDA257 form ineffective nodules with aberrant ultrastructure. Appl. Environ. Microbiol. 69:3561-3568

Leigh, J. A., and Walker, G. C. 1994. Exopolysaccharides of Rhizobium: Synthesis, regulation and symbiotic function. Trends Genet. 10:6367.

Lerner, C. G., Gulati, P. S., and Inouye, M. 1995. Cold-sensitive conditional mutations in Era, an essential Escherichia coli GTPase, isolated by localised random polymerase chain reaction mutagenesis. FEMS (Fed. Eur. Microbiol. Soc.) Microbiol. Lett. 126:291-298.

Lodwig, E. M., Hosie, A. H., Bourdes, A., Findlay, K., Allaway, D., Karunakaran, R., Downie, J. A., and Poole, P. S. 2003. Amino-acid cycling drives nitrogen fixation in the legume-Rhizobium symbiosis. Nature 422:722-726.
Long, S. R. 2001. Genes and signals in the Rhizobium-legume symbiosis. Plant Physiol. 125:69-72.

McDermott, T. R., and Kahn, M. L. 1992. Cloning and mutagenesis of the Rhizobium meliloti isocitrate dehydrogenase gene. J. Bacteriol. 174:47904797.

Mellor, R. B. 1989. Bacteroids in the Rhizobium-legume symbiosis inhabit a plant internal lytic compartment: Implications for other microbial endosymbioses. J. Exp. Bot. 40:831-839.

Mortimer, M. W., McDermott, T. R., York, G. M., Walker, G. C., and Kahn, M. L. 1999. Citrate synthase mutants of Sinorhizobium meliloti are ineffective and have altered cell surface polysaccharides. J. Bacteriol. 181:7608-7613.

Niehaus, K., Kapp, D., and Pühler, A. 1993. Plant defence and delayed infection of alfalfa pseudonodules induced by exopolysaccharide (EPSI) deficient Rhizobium meliloti mutant. Planta 190:415-425.

Parsons, R., and Sunley, R. J. 2001. Nitrogen nutrition and the role of rootshoot nitrogen signaling particularly in symbiotic systems. J. Exp. Bot. 52:435-443.

Patriarca, E. J., Tate, R., and Iaccarino, M. 2002. Key role of bacterial $\mathrm{NH}_{4}{ }^{+}$metabolism in Rhizobium-plant symbiosis. Microbiol. Mol. Biol. Rev. 66:203-222.

Quandt, J., and Hynes, M. F. 1993. Versatile suicide vectors which allow direct selection for gene replacement in gram-negative bacteria. Gene 127:15-21.

Rice, W. A., and Olsen, P. E. 1988. Root-temperature effects on competition for nodule occupancy between two Rhizobium meliloti strains. Biol. Fertil. Soils 6:137-140.

Sakano, H., Yamada, S., Ikemura, T., Shimura, Y., and Ozeki, H. 1974. Temperature sensitive mutants of Escherichia coli for tRNA synthesis. Nucleic Acids Res. 1:355-371.

Sambrook, J., Fritsch, E. F., and Maniatis, T. 1989. Molecular Cloning: A Laboratory Manual. 2nd ed. Cold Spring Harbor Laboratory Press, Cold Spring Harbor, NY, U.S.A.

Somerville, J. E., and Kahn, M. L. 1983. Cloning of the glutamine synthetase I gene from Rhizobium meliloti. J. Bacteriol. 156:168-176.

Spaink, H. P., Kondorosi, A., and Hooykaas, P. J. J. 1998. The Rhizobiaceae: Molecular Biology of Model Plant-Associated Bacteria. Kluwer Academic, Dordrecht, The Netherlands.

Srere, P. A. 1969. Citrate synthase. Methods Enzymol. 13:3-11.

Stougaard, J. 2000. Regulators and regulation of legume root nodule development. Plant Physiol. 124:531-540.

Thony-Meyer, L., and Kunzler, P. 1996. The Bradyrhizobium japonicum aconitase gene $(a c n A)$ is important for free-living growth but not for an effective root nodule symbiosis. J. Bacteriol. 178:6166-6172.

Udvardi, M. K., and Day, D. A. 1997. Metabolite transport across symbiotic membranes of legume nodules. Annu. Rev. Plant Physiol. Plant Mol. Biol. 48:493-523.

Urzainqui, A., and Walker, G. C. 1992. Exogenous suppression of the symbiotic deficiencies of Rhizobium meliloti exo mutants. J. Bacteriol. 174:3403-3406.

Wood, D. O., Atkinson, W. H., Sikorski, R. S., and Winkler, H. H. 1983. Expression of the Rickettsia provazekii citrate synthase gene in Escherichia coli. J. Bacteriol. 155:412-416.

Zhao, H., and Arnold, F. H. 1997. Optimization of DNA shuffling for high fidelity recombination. Nucleic Acids Res. 25:1307-1308. 